May 1999 • NREL/CP-520-26374

\title{
Structural Changes in a-Si:H Films Deposited on the Edge of Crystallinity
}

A.H. Mahan

National Renewable Energy Laboratory

J. Yang, and S. Guha

United Solar Systems Corp., Troy, Michigan

D.L. Williamson

Colorado School of Mines, Golden, Colorado

Presented at the Materials Research Society

Spring Conference

San Francisco, California

April 6-10, 1999

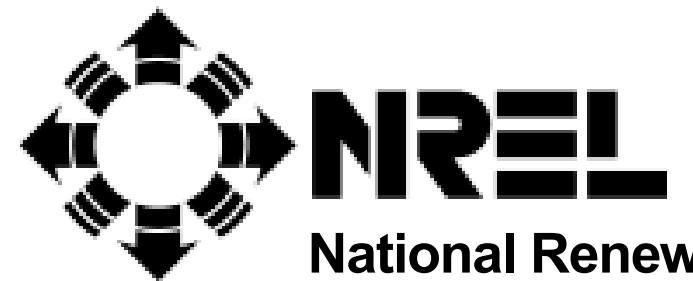

1617 Cole Boulevard

Golden, Colorado 80401-3393

NREL is a U.S. Department of Energy Laboratory

Operated by Midwest Research Institute $\bullet$ Battelle $\bullet$ Bechtel

Contract No. DE-AC36-98-G010337 


\section{NOTICE}

This report was prepared as an account of work sponsored by an agency of the United States government. Neither the United States government nor any agency thereof, nor any of their employees, makes any warranty, express or implied, or assumes any legal liability or responsibility for the accuracy, completeness, or usefulness of any information, apparatus, product, or process disclosed, or represents that its use would not infringe privately owned rights. Reference herein to any specific commercial product, process, or service by trade name, trademark, manufacturer, or otherwise does not necessarily constitute or imply its endorsement, recommendation, or favoring by the United States government or any agency thereof. The views and opinions of authors expressed herein do not necessarily state or reflect those of the United States government or any agency thereof.

Available to DOE and DOE contractors from:

Office of Scientific and Technical Information (OSTI)

P.O. Box 62

Oak Ridge, TN 37831

Prices available by calling 423-576-8401

Available to the public from:

National Technical Information Service (NTIS)

U.S. Department of Commerce

5285 Port Royal Road

Springfield, VA 22161

$703-605-6000$ or $800-553-6847$

or

DOE Information Bridge

http://www.doe.gov/bridge/home.html

Printed on paper containing at least $50 \%$ wastepaper, including $20 \%$ postconsumer waste 


\title{
STRUCTURAL CHANGES IN a-Si:H FILMS DEPOSITED ON THE EDGE OF CRYSTALLINITY
}

\author{
A. H. Mahan, J. Yang*, S. Guha*, and D. L. Williamson** \\ National Renewable Energy Laboratory, Golden, CO 80401 \\ *United Solar Systems Corp., Troy, MI 48084 \\ **Colo. School of Mines, Golden, CO 80401
}

\section{ABSTRACT}

Using infrared, $\mathrm{H}$ evolution and $\mathrm{x}$-ray diffraction (XRD), the structure of high $\mathrm{H}$ dilution, glow discharge deposited a-Si:H films "on the edge of crystallinity" is examined. From the $\mathrm{Si}-\mathrm{H}$ wag mode peak frequency and the XRD results, we postulate the existence of very small Si crystallites contained within the amorphous matrix, with the vast majority of the bonded $\mathrm{H}$ located on these crystallite surfaces. Upon annealing at ramp rates of $8-15^{\circ} \mathrm{C} / \mathrm{min}$, a $\mathrm{H}$ evolution peak at $\sim 400^{\circ} \mathrm{C}$ appears, and film crystallization is observed at temperatures as low as $500^{\circ} \mathrm{C}$, both of which are far below those observed for a-Si:H films grown without $\mathrm{H}$ dilution using similar ramp rates. While the crystallite volume fraction is too small to be detected by XRD in the as-grown films, these crystallites catalyze the crystallization of the remainder of the amorphous matrix upon moderate annealing, thus explaining the existence of the low temperature $\mathrm{H}$ evolution peak.

\section{INTRODUCTION}

Hydrogenated amorphous silicon (a-Si:H) films, deposited by the glow discharge (GD) process using silane highly diluted in hydrogen, have become increasingly important both from a technological as well as a scientific point of view. Since the first observation that $\mathrm{H}$ dilution led to an improved stability (1), this process has been used extensively in the production of a-Si:H films and solar cells. It has been well established not only (a) that increasing $\mathrm{H}$ dilution leads eventually to the deposition of microcrystalline silicon ( $\mu \mathrm{c}-\mathrm{Si}$ ) (2), but also (b) that the improved stability of the a-Si:H films as well as solar cells, deposited using $\mathrm{H}$ dilution, has been obtained using films deposited "on the edge of crystallinity" $(3,4)$. However, several experimental factors such as film thickness and substrate effects $(5,6)$ suggest that it is not easy to identify and investigate this material in a cohesive (consistent) fashion.

Nevertheless, new information is starting to emerge regarding the properties of these "on the edge" materials. A succession of papers has examined properties of "on the edge" a-Si:H films deposited by the same group using high $\mathrm{H}$ dilution. Xu et al. (7) first reported the existence of a low temperature $\mathrm{H}$ evolution peak and an anisotropic (columnar-like) structure effect as measured by SAXS. Tsu et al. (4) then reported, as seen by TEM, the existence of large linearlike objects; these were interpreted, with the help of a shifted Raman peak, to be intermediate in order between the continuous random network (amorphous) and crystalline phases. These (randomly oriented) objects appeared even for films deposited using undiluted disilane, and the number of these objects increased at high $\mathrm{H}$ dilution. Finally, Guha et al. (8) showed that the width of the first $\mathrm{x}$-ray diffraction (XRD) peak narrowed at high $\mathrm{H}$ dilution, and that this narrowing was suggestive of an improvement in medium range order.

In this work we examine, from a different perspective, "on the edge" films deposited by the same group using infrared (IR) spectroscopy, XRD, H evolution, and (partial) annealing. We find that, even though the XRD shows no evidence of crystallinity and the peak frequency of the IR active stretch mode remains at $2000 \mathrm{~cm}-1$, indicating monohydride bonding associated with device quality a-Si:H, the peak frequency of the $\mathrm{Si}-\mathrm{H}$ wag mode shifts downward from $\sim 640 \mathrm{~cm}$ 1 to $620 \mathrm{~cm}-1$ at high $\mathrm{H}$ dilution. This latter frequency is identified as being due to $\mathrm{H}$ bonded on crystalline Si surfaces (9). This shift in peak position suggests that, even though the matrix is still almost completely amorphous, the vast majority of the $\mathrm{H}$ is bonded on the surfaces of $\mathrm{Si}$ 
crystallites. We show that the only way to simultaneously satisfy the IR (H content) and XRD (sensitivity) results is for these crystallites to be very small and to be randomly oriented. Under these conditions, we estimate that the crystallite volume fraction (vf) can be $\sim 5-10 \%$. Although this vf is still too small for the grain boundary precursors to serve as $\mathrm{H}$ percolation (evolution) pathways, thus explaining the existence of the low temperature $\mathrm{H}$ evolution peak, the crystallites serve as nucleation sites for further crystallization after sample annealing. That is, as there is no nucleation barrier to overcome upon sample heating, such samples can be expected to crystallize at annealing temperatures far lower than samples which are entirely amorphous (10). Indeed, crystallinity is detected some $200^{\circ} \mathrm{C}$ lower in "on the edge" samples as compared to fully amorphous samples comparably annealed (11), thus (indirectly) confirming the existence of these small Si crystallites.

\section{EXPERIMENT}

An extensive series of intrinsic films were deposited by the glow discharge (GD) process at varying levels of $\mathrm{H}$ dilution, all at a deposition temperature of $300^{\circ} \mathrm{C}$, onto c-Si substrates. Three different $\mathrm{H}$ dilutions were used; "no dilution", "low dilution", and "high dilution". The "high dilution" films used in solar cells demonstrate high efficiency and improved stability (3). Sample thicknesses ranged from 0.5-1.05 $\mu \mathrm{m}$. IR measurements were performed using a dual beam Perkin-Elmer 580-B Spectrometer, with an instrumental resolution of $2.3 \mathrm{~cm}-1$. Transmission data, after appropriate baseline subtraction, were transformed into absorption peak profiles using the analysis of Brodsky et al. (12). H evolution was performed using ramp rates between $\sim 6-14^{\circ} \mathrm{C} / \mathrm{min}$, with the rates adjusted such that the total time in the $\mathrm{H}$ evolution furnace for each (piece of) film was $\sim 1 \mathrm{hr}$. For step-wise evolution experiments on films which were later examined for crystallinity, the samples were promptly removed from the $\mathrm{H}$ evolution apparatus when the ramp temperature reached the appropriate value; these temperatures were $400^{\circ}, 500^{\circ}$, and $700^{\circ} \mathrm{C}$ respectively.. The XRD measurements were carried out with a Siemens D-500 Diffractometer operating with $\mathrm{Cu}-\mathrm{K} \alpha$ radiation in the Bragg-Brentano geometry. Long counting times were used to achieve good signal-to-noise ratios.

\section{RESULTS}

Figure 1 shows IR spectra for (a) the $\mathrm{Si}-\mathrm{H}$ stretch and (b) wag modes for the "no dilution" and "high dilution" films; both film thicknesses were $\sim 1.0 \mu \mathrm{m}$. The "high dilution" film was seen by SEM to lift off from its substrate while remaining intact structurally. Although there exists some difference in the stretch mode shape, the peak frequencies are both centered around $2000 \mathrm{~cm}-1$, indicating predominantly monohydride $(\mathrm{Si}-\mathrm{H})$ bonding, and thus state-of-theart device quality. From Figure $1 \mathrm{~b}$, the film $\mathrm{H}$ contents $(\mathrm{CH})$ do not change appreciably with dilution; that is, the $\mathrm{CH}$ is 9.6 and 8.2 at.\% respectively for the "no dilution" and "high dilution" films. The wag mode full width at half maximum (FWHM) for the films are also almost identical (100 cm-1), a value typical of device quality a-Si:H films containing similar $\mathrm{CH}$. On the other hand, the wag mode peak frequency is seen to shift from $635-640 \mathrm{~cm}-1$ for the "no dilution" film to $\sim 620 \mathrm{~cm}-1$ for the "high dilution" film. Although the former peak frequency is typical for "standard" a-Si:H (13), the latter lies distinctly outside this frequency range.

We consider it significant that the wag frequency of $\mathrm{H}$ bonded in the monohydride $(\mathrm{Si}-\mathrm{H})$ configuration on both the c-Si (100) and (111) surfaces is identically at $\sim 620 \mathrm{~cm}-1$ (9). Although $\mathrm{H}$ bonded in other $(\mathrm{SiH} 2,(\mathrm{SiH} 2) \mathrm{n})$ configurations on c-Si can show a wide variety of peak frequencies (from $620 \mathrm{~cm}-1$ to as high as $675 \mathrm{~cm}-1$ ) (14), for purely $\mathrm{Si}-\mathrm{H}$ monohydride bonding only one wag mode frequency is observed. Hence, combining these observations with the present measurements, we assert that the IR frequency shift for the "high dilution" film indicates the presence of crystallites contained within the amorphous matrix, with the large majority of the $\mathrm{H}$ bonded on these crystallite surfaces.

This is to be contrasted with XRD data. This is seen in Figure 2, where the XRD intensity for the "no dilution" and "high dilution" sample is plotted vs. the scattering angle $2 \theta$ 

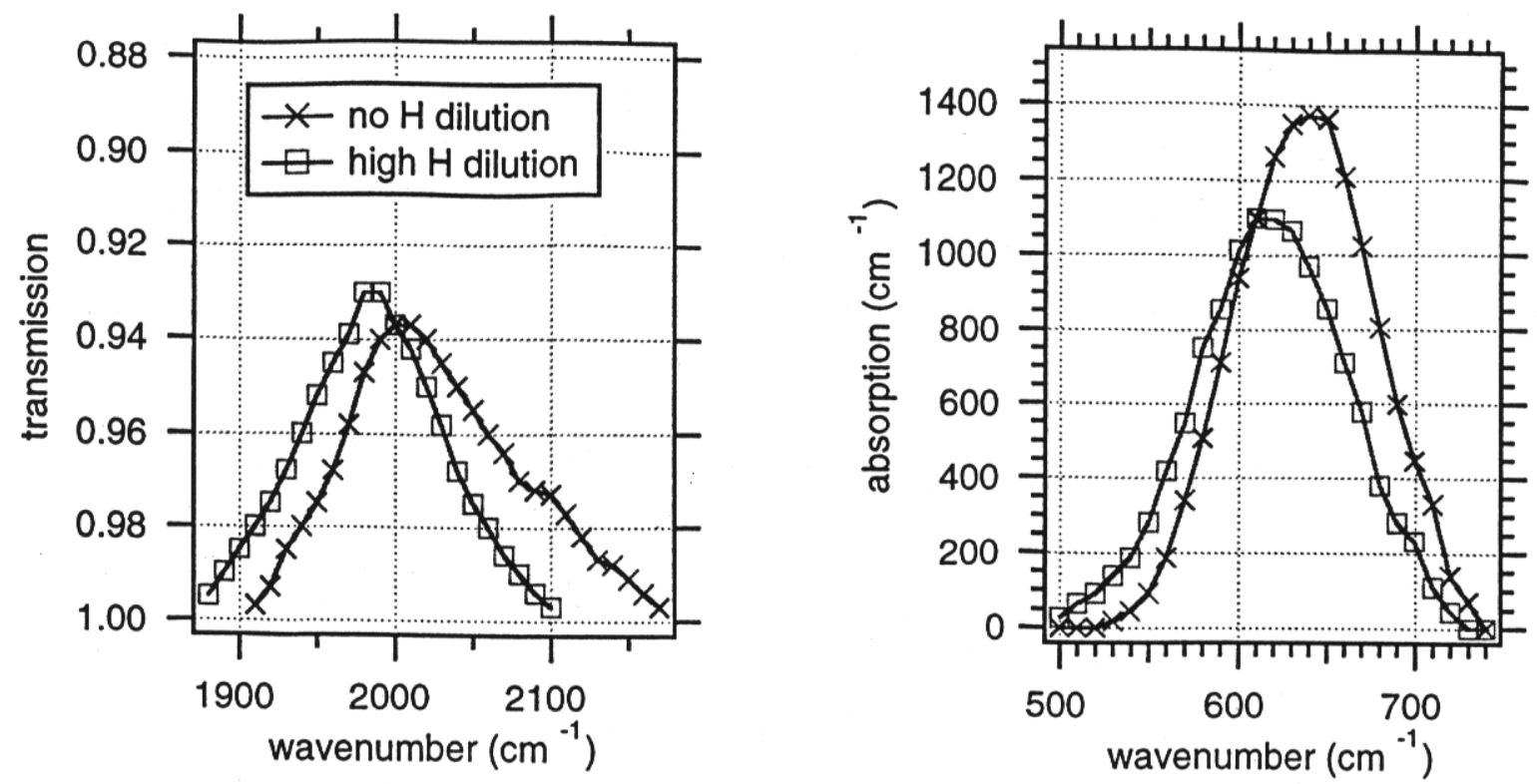

Figure 1. (a) IR stretch mode peak position (b) and wag mode absorption spectra for the "no dilution" and the "high dilution" a-Si:H samples.

from $15^{\circ}-60^{\circ}$. Also noted are the angular positions where the first three peaks in powdered (randomly oriented) c-Si (the (111), (220), and (311) crystal orientations) would occur. The breaks in the curves correspond to second order diffraction effects from the c-Si substrate, which are omitted. As can be seen, the only features observed in the spectrum are the strong (first amorphous) peak occurring at roughly $28.5^{\circ}$, and a less intense (second amorphous) peak occurring at $\sim 51^{\circ}$. The substrate reference is included for comparison. Based on these results, both films appear to be fully amorphous.

The problem, then, is to reconcile these two sets of measurements. That is, we must, for the "high dilution" film, understand how to incorporate enough crystallinity into the sample to enable enough $\mathrm{H}$ bonding on the surfaces of these crystallites to account for the majority $(>5$ at.\%) of the bonded $\mathrm{H}$ (thus satisfying the wag mode peak frequency shift), while at the same time not generating any detectable crystalline features in the XRD spectrum. We address this by

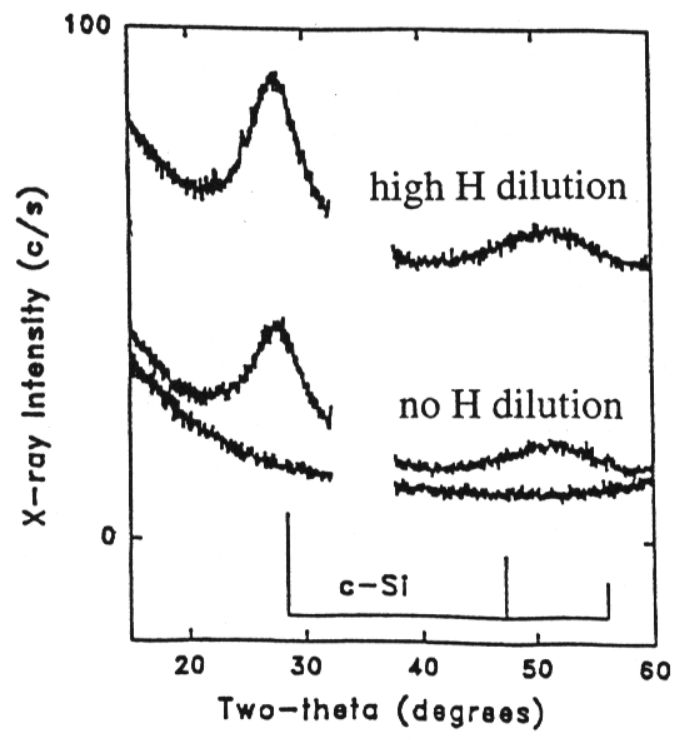

Figure 2. X-ray intensity vs. $2 \theta\left({ }^{\circ}\right)$ considering crystallite size. From the Scherrer formula and the XRD sensitivity, we estimate that large c-Si crystallites $(>50 \AA)$, yielding sharp diffraction peaks, can easily be distinguished from any (broad) amorphous diffraction signal with a sensitivity of $1-2 \%$ in vf. On the other hand, the first XRD peak FWHM of the 'high dilution' a-Si:H film is $\sim 5^{\circ}(8)$, so if the dimension of any crystallites contained within the film were reduced from the $>50 \AA$ size previously discussed to $\sim 15-20 \AA$, the XRD FWHM of these crystallites now becomes comparable to the width of the amorphous XRD signal. The only method of distinguishing these (smaller) crystallites from the (first XRD peak) amorphous feature now becomes the very small difference in peak positions, and crystallite detection is becomes more difficult than before, enabling an upper "adjustment" in the vf limit. Going further with this argument, the existence of even smaller crystallites, on the order of $\sim 10 \AA$ in 


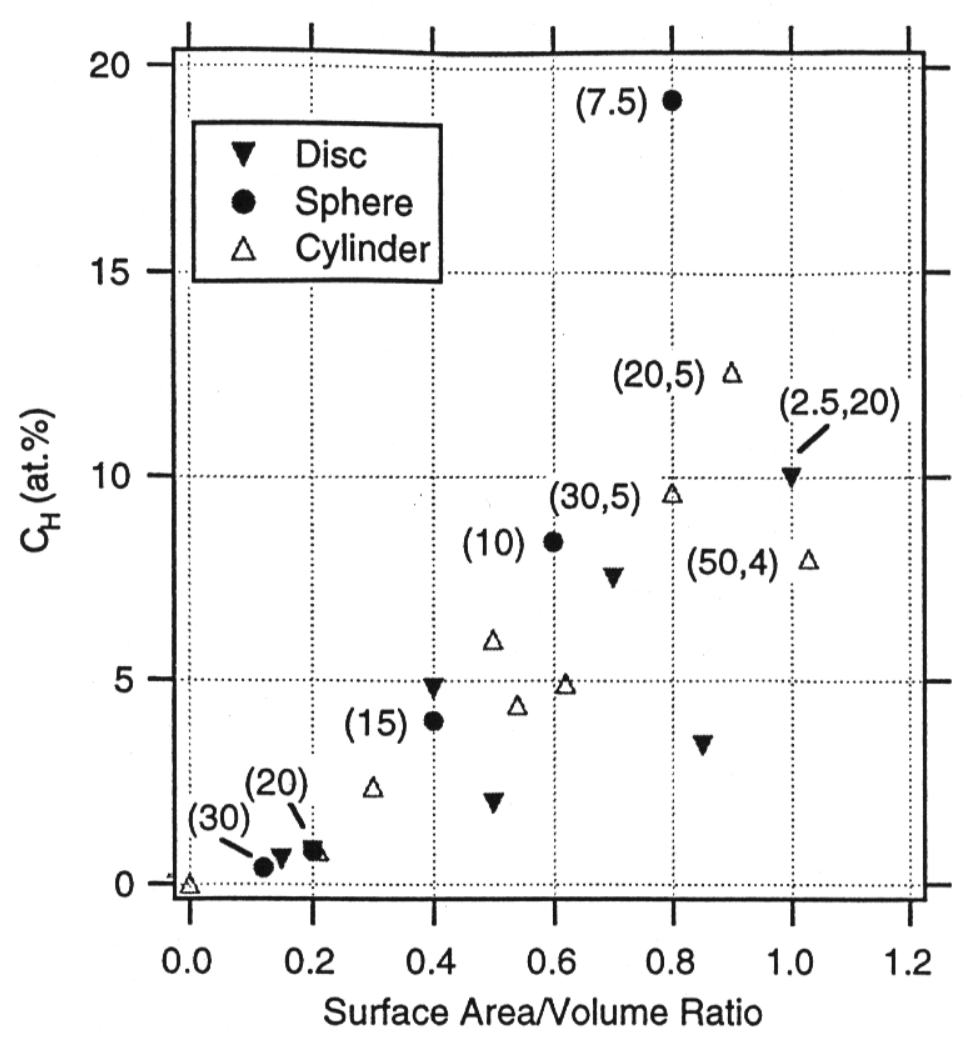

Figure 3. $\mathrm{CH}$ vs. crystallite surface area/volume ratio.

diameter, which produce even broader XRD features, would be even more difficult to detect. Thus, size arguments alone can enable the existence of a considerably larger real crystallite volume fraction than that given by our initial estimate (1-2\%). In Figure 3 we summarize numerically the arguments made in the preceding paragraph. In making this figure, we have assumed an upward sliding scale in vf vs. decreasing crystallite size, with a sensitivity limit of $5 \%$ for crystallite sizes of $15-20 \AA$ (yielding XRD FWHM's of $\sim 5^{\circ}$ ), and a limit of $8 \%$ for even smaller crystallites having sizes of $10-15 \AA$ (yielding XRD FWHM's of $>9^{\circ}$ ). Using Aw $=2.3 \mathrm{e} 19 / \mathrm{cm} 3(15)$ and assuming a $\mathrm{H}$ coverage density of $1 \mathrm{e} 15 / \mathrm{cm} 2$ on $\mathrm{c}-\mathrm{Si}$ surfaces (16), we plot the total amount of $\mathrm{H}$ on these crystallites vs. the crystallite surface area/volume ratio. We consider spheres, discs, and cylinders, with representative dimensions in $\AA$ (length, diameter) noted in the figure; for crystallites with a large eccentricity, we assume a random orientation in the film (7) and take the average of the three dimensions to be the size detected by XRD (17). We note some scatter in the data. This is ascribed to different surface area/volume ratios for crystallites of different shapes as well as the fact that crystallites having one large dimension weight the averaged dimension as seen by XRD to larger values; hence, in our model, a lower $\mathrm{CH}$ is thus observed for these crystallites due to the higher XRD sensitivity. However, the overall trend is easily seen. That is, large crystallites have small surface area/volume ratios, and we are unable to put enough bonded $\mathrm{H}$ on the surfaces to satisfy the IR results, while for small crystallites with large surface area/volume ratios, we exceed our 5 at.\% $\mathrm{H}$ limit for all three shapes. Thus, we are able to satisfy the XRD and the IR results simultaneously by considering the inclusion of small crystallites within an amorphous matrix

Finally, given the presence of small crystallites in our "high dilution" a-Si:H film (up to a $\mathrm{vf}=5-10 \%$ ), we now examine in this context the $\mathrm{H}$ evolution results (6). That is, we need to explain the existence of a $\mathrm{H}$ evolution peak that occurs at a temperature $\sim 100^{\circ} \mathrm{C}$ lower than observed in "standard" a-Si:H films of similar thickness (18). To do this, we partially anneal pieces of our films up to $400^{\circ}, 500^{\circ}$, and $700^{\circ} \mathrm{C}$, respectively, in our $\mathrm{H}$ evolution furnace, and then examine them for crystallinity. While the "high dilution" film remains amorphous after the $400^{\circ} \mathrm{C}$ anneal, crystallinity is observed after the $500^{\circ} \mathrm{C}$ anneal, and after the $700^{\circ} \mathrm{C}$ anneal the 
film appears to be almost fully crystallized. From the IR, $40 \%(75 \%)$ of the bonded $\mathrm{H}$ is lost after the $400^{\circ} \mathrm{C}\left(500^{\circ} \mathrm{C}\right)$ anneal, while no bonded $\mathrm{H}$ remains after the $700^{\circ} \mathrm{C}$ anneal. This is to be contrasted with results for 'standard' a-Si:H, which lose almost no bonded $\mathrm{H}$ at low $\left(400^{\circ} \mathrm{C}\right)$ anneal temperatures and crystallize only at very high temperatures $\left(>750^{\circ} \mathrm{C}\right)(11)$. In addition, low $\mathrm{CH}$ films deposited by the hot wire (HW) technique, which exhibit as similar narrowing of the first XRD peak (19), also show no crystallinity when annealed in a similar fashion.

\section{DISCUSSION}

While acknowledging the strong substrate dependence on film structural properties, as well as the sensitivity of film structure to small changes in film deposition conditions for films in this "on the edge" region, we nevertheless comment on how the present results add to the structural picture emerging for these films. In particular, they add to and extend the results of Tsu et al. (7). In that publication, TEM and Raman measurements showed the existence of "somewhat ordered linear-like objects", which were randomly oriented, and which made up from Raman about $10-15 \%$ of the total Raman signal. Assuming that this percentage relates to volume fraction, the similarity of those results to that of the present work, particularly the magnitude of the vf, is highly suggestive. In particular, we suggest that the "objects" discussed by Tsu et al. (7) may in fact be crystallites, that those objects observed by TEM must be those at the very extreme (upper) end of a Gaussian size distribution, and that most of these crystallites must be very small in size. Further, we show how the presence of crystallites in an a-Si:H matrix explains the existence of the low temperature $\mathrm{H}$ evolution peak seen by $\mathrm{Xu}$ et al. (6). It is well known, for a low temperature $\mathrm{H}$ evolution peak to occur, that some sort of connective path to the surface (microvoids, grain boundaries) is needed. By both accounts (Mahan, Tsu), the vf of the present as grown films $(5-10 \%, 10-15 \%)$ is not large enough for percolation to occur unless these objects are highly oriented; yet, in both cases this preferential orientation is not seen to occur. On the other hand, if small crystallites already exist in the as grown material, there is no nucleation barrier to overcome upon low temperature sample annealing (10). Therefore, the existing crystallites can grow rapidly in size with moderate annealing, enabling $\mathrm{H}$ to effuse out of the film along the suddenly accentuated grain boundaries, and thus contribute to the low temperature $\mathrm{H}$ evolution peak. However, these are not grain boundaries in the traditional sense, as they exhibit only one of the two IR signatures commonly observed (the wag mode shift). That is, traditional grain boundaries in $\mu \mathrm{c}-\mathrm{Si}$ show a shift in both the stretch and wag mode peak frequencies (2); as mentioned previously, the peak frequency of the stretch mode of the present "high dilution" sample remains at $2000 \mathrm{~cm}-1$, which is not indicative of $\mathrm{H}$ bonded on c-Si surfaces. We note, however, that the present results are in fact not in contradiction to the existing literature, as Rath et al. (20) have shown that very compact grain boundaries (compact in the sense that the stretch mode peak position is still at $2000 \mathrm{~cm}-1)$ can in fact occur in $\mu \mathrm{c}-\mathrm{Si}$.

Finally, we comment on the better lattice ordering, postulated to occur by Tsu et al. (7) and recently observed by XRD by Guha et al. (8) for the "high dilution" films. Both publications agree that a more ordered structure is produced using high $\mathrm{H}$ dilution. We note, however, that a more ordered structure has been previously been obtained, as observed by XRD, with low $\mathrm{CH}$ films deposited by the HW technique (19). In those films, NMR measurements (21) showed that $\mathrm{H}$ clustering in the HW films was so enhanced, and the $\mathrm{CH}$ so low, that there existed large spatial regions without appreciable $\mathrm{H}$; from $\mathrm{XRD}$, these regions were observed to be better ordered. We postulate that the same thing is happening in these high $\mathrm{H}$ dilution GD films, but for a different reason. What may be needed deposition-wise to produce the narrower XRD FWHM is a method to produce a $\mathrm{H}$ spatial inhomogeneity throughout an a-Si:H film; what results are regions containing minimal $\mathrm{H}$ with better ordering. In the $\mathrm{HW}$ films, on the one hand, higher $\mathrm{H}$ clustering and lower $\mathrm{CH}$ produced these better ordered (devoid of $\mathrm{H}$ ) regions, while for the present high $\mathrm{H}$ dilution films, $\mathrm{H}$ preferentially bonded on the surfaces of the small crystallites serves the same function. 


\section{CONCLUSIONS}

We have examined GD a-Si:H films, deposited "on the edge of crystallinity" using high $\mathrm{H}$ dilution, by IR, $\mathrm{H}$ evolution and XRD. The $\mathrm{Si}-\mathrm{H}$ wag mode peak position, along with the XRD results, are interpreted as evidence for the existence of very small Si crystallites contained within the as-grown amorphous matrix, with the vast majority of the bonded $\mathrm{H}$ located on these crystallite surfaces. Upon annealing, a low temperature $\mathrm{H}$ evolution peak appears, and film crystallization is observed at temperatures as low as $500^{\circ} \mathrm{C}$, which is far below that observed for a-Si:H films deposited without $\mathrm{H}$ dilution. While the crystallite vf is too small to be detected by $\mathrm{XRD}$ in the as-grown films, the crystallites catalyze the crystallization of the remainder of the amorphous lattice after annealing, thus providing a connectivity path to the surface and explaining the existence of the low temperature $\mathrm{H}$ evolution peak.

\section{ACKNOWLEDGEMENTS}

The authors thank F. Hassoon and M. al Jassim for SEM measurements, W. Beyer for many stimulating discussions and ideas relating to this work, and L. Gedvillas and J. D. Webb for IR measurement support. The research at NREL, United Solar, and the Colorado School of Mines was supported by the U. S. Department of Energy under subcontracts DE-AC36-98-GO10337, ZAK-8-17619-09, and XAF-8-17619-05 respectively.

\section{REFERENCES}

1. S. Guha, K. L. Narasimhan, and S. M. Pieruszko, J. Appl. Phys. 52 (1981) 859.

2. U. Kroll, J. Meier, A. Shah, S. Mikhailov, and J. Weber, J. Appl. Phys. 80 (1996) 4971.

3. J. Yang, A. Banerjee, and S. Guha, Appl. Phys. Lett. 70 (1997) 2975.

4. D. V. Tsu, B. S. Chao, S. R. Ovshinsky, S. Guha, and J. Yang, Appl. Phys. Lett. 71 (1997) 1317.

5. P. Roca i Cabarrocas, N. Layadi, T. Heitz, B.Drevillon, and I. Solomon, Appl .Phys. Lett. 66 (1995) 3609.

6. J. Koh, Y. Lee, H. Fujiwara, C. R. Wronski, and R. W. Collins, Appl. Phys. Lett. 73 (1998) 1526.

7. X. Xu, J. Yang, and S. Guha, J. non-Cryst. Sol. 198-200 (1996) 60.

8. S. Guha, J. Yang, D. L. Williamson, Y. Lubianiker, J. D. Cohen, and A. H. Mahan, Appl. Phys. Lett. 74, 1999, in press.

9. H. Wagner and W. Beyer, Solid State Comm. 48 (1983) 585.

10. R. B. Iverson and R. Reif, J. Appl. Phys. 62 (1987) 1675.

11. W. Beyer, private communication.

12. M. H. Brodsky, M. Cardona, and J. J. Cuomo, Phys. Rev. B 16 (1977) 3556.

13. W. Beyer, in Semiconductors and Semimetals, N. Nickel, Ed. (Academic Pr., 1999), p.165.

14. J. A. Schaefer, T. Balster, V. Polyakov, U. Rossow, S. Sloboshanin, U. Starke, and F. S. Tautz, MRS Proc. 513 (1998) 3.

15. A. A. Langford, M. L. Fleet, B. P. Nelson, W. A. Lanford, and N. Maley, Phys. Rev. B45 (1992) 13367.

16. R. J. Culbertson, L. C. Feldman, P. J. Silverman, and R. Haight, J. Vac.Sci. Tech. 20 (1982) 868.

17. B. E. Warren, X-Ray Diffraction, Dover Publications (New York, 1990), pg. 256.

18. W. Beyer, in Tetrahedrally Bonded Amorphous Semiconductors, D. Adler and H. Fritzsche, Eds. (Plenum, 1985), pg. 129.

19. A. H. Mahan, D. L. Williamson, and T. E. Furtak, MRS Symp. Proc. 467 (1997) 657.

20. J. K. Rath, A. Barbon, and R. E. I. Schropp, J. non-Cryst. Solids 227-230, 1277 (1998).

21. Y. Wu, J. T. Stephen, D. X. Han, J. M. Rutland, R. S. Crandall, and A. H. Mahan, Phys. Rev. Lett. 77 (1996) 2049. 